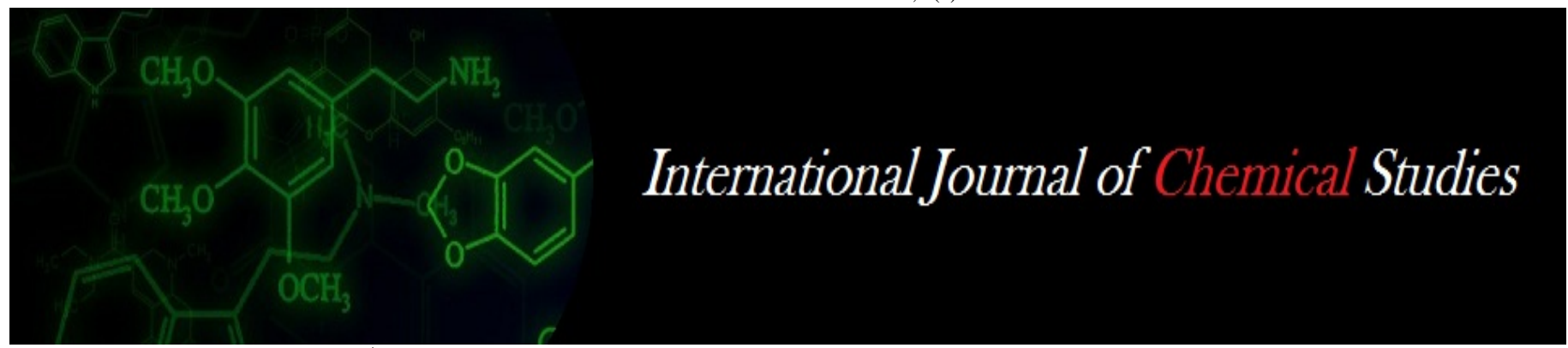

P-ISSN: 2349-8528

E-ISSN: 2321-4902

www.chemijournal.com

IJCS 2020; 8(4): 3881-3883

(C) 2020 IJCS

Received: 13-05-2020

Accepted: 25-06-2020

\section{P Subramanian}

Professor and Head,

Department of Renewable

Energy Engineering

Agricultural Engineering

College and Research Institute

Tamil Nadu Agricultural

University Coimbatore, Tamil

Nadu, India

J Gitanjali

Teaching Assistant, Department

of Renewable Energy

Engineering Agricultural

Engineering College and

Research Institute Tamil Nadu

Agricultural University

Coimbatore, TamilNadu, India

\section{K Nithya}

Ph.D. Scholar, Department of

Renewable Energy Engineering

Agricultural Engineering College

and Research Institute Tamil

Nadu Agricultural University

Coimbatore, TamilNadu, India

\section{B Prabha}

Research Associate, Department of Renewable Energy

Engineering Agricultural

Engineering College and

Research Institute Tamil Nadu

Agricultural University

Coimbatore, TamilNadu, India

\section{Investigation on thermal degradation of bamboo (Bambusa vulgaris) culm at varied heating rates through TG analyzer}

\author{
P Subramanian, J Gitanjali, K Nithya and B Prabha
}

DOI: https://doi.org/10.22271/chemi.2020.v8.i4aw.10256

\begin{abstract}
Bamboo biomass is considered as a renewable energy source due to its intrinsic energy and regrow in a comparatively shorter time. Bamboo stem is called as culm which can be thermo chemically processed to produce energy in the form of solid (charcoal) liquid (biooil) and gaseous (syn gas) products. To assess the potential for thermal energy generation, thermogravimetric analysis of bamboo culm at four different heating rates $\left(10,20,30\right.$ and $\left.40{ }^{\circ} \mathrm{C} \mathrm{min}-1\right)$ was performed. Thermogravimetry and derivative thermogravimetry plots at selected heating rates revealed that better moisture removal $\left(0.84 \%{ }^{\circ} \mathrm{C}^{-1}\right)$ at $20^{\circ} \mathrm{C} \mathrm{min}-1$; higher cellulose and hemicellulose degradation $\left(7.00 \%{ }^{\circ} \mathrm{C}^{-1}\right)$ at $30^{\circ} \mathrm{C} \mathrm{min}^{-1}$ and faster rate of degradation of higher volatiles and carbon $\left(1.62 \%{ }^{\circ} \mathrm{C}^{-1}\right)$ at $20^{\circ} \mathrm{C} \mathrm{min}^{-1}$. It can be used to design the thermochemical conversion units for the processing of solid biomass into energy and chemical derivatives.
\end{abstract}

Keywords: bamboo, culm, thermogravimetric analysis, heating rate.

\section{Introduction}

Bamboo biomass energy has greater potential to substitute conventional fossil fuels. Bamboo biomass can be processed in various thermal chemical conversion techniques (pyrolysis, combustion and gasification) to produce solid or liquid or gaseous energy products (charcoal, biooil and syngas), these can be used as an alternative for existing fossil fuel. Among various biomass energy conversion routes, thermochemical conversion route is a dominated one in terms of thermal efficiency and ease of processing. In order to assess the feasibility assessment of energy generation from any biomass, proper characterization and evaluation is necessary. As it is a costlier and time-consuming process, thermogravimetric analysis (TGA) of biomass sample is considered as a reliable and sensitive method to characterize the biomass in shorter time with lesser sample quantity. Thermo gravimetric analysis (TGA) is used to determine the change in weight of the sample with respect to change in temperature. TGA curve alone may not be sufficient to interpret the weight loss of the sample. Hence, a derivative thermo gravimetric curve along with TGA curve is needed to determine the apparent weight loss of samples. The rate of degradation of testing materials subjected to TGA is an indication of thermal behavior of biomass under inert condition. TG studies with varied heating rates at inert atmosphere will result in significant information to interpret for viability of thermochemical conversion route as well as the degradation nature of various components of the biomass at increased temperatures.

\section{Material and Methods}

Preparation of bamboo culm

The freshly cut bamboo culm harvested from the field is size reduced and pulverized. The pulverized sample is sieved in a sieve (size:1mm). The biomass sample of size $\leq 1$ is used for the thermogravimetric analysis.

\section{Thermogravimetric analysis}

The thermal decomposition behavior of biomass is studied by TGA Q50 instrument (TA Instruments, US). The biomass of $5 \pm 3 \mathrm{mg}$ is placed on the sample holder and in nitrogen 
atmosphere in each experiment. The nitrogen flow rate was kept constant at $60 \mathrm{ml} \mathrm{min}{ }^{-1}$. Thermal decomposition is carried out at non-isothermal conditions. TGA data were taken at heating rates of $10,20,30$ and $40^{\circ} \mathrm{C} \mathrm{min}{ }^{-1}$ in the temperature range of 30 to $900{ }^{\circ} \mathrm{C}$ (Saddawi et al., 2010) ${ }^{[5]}$. The weight loss of biomass sample was recorded as a function of time and temperature using TA software. The weight loss curve is plotted against temperature. It provided a range of temperature at which the maximum thermal degradation of bamboo culm was observed.

\section{Results and discussion}

TGA of bamboo culm is performed in a nitrogen atmosphere, at four different heating rates in TGA instrument to study the nature of thermal degradation. Three distinguished phases of degradation was observed in the resultant graphs and the temperature range (initial and final point) of these phases are determined by the tangent intersection at ascending and descending points of linear line (Kumar et al., 2008) ${ }^{[2]}$. The effect of heating rate on the temperature range of each phase and weight losses during the thermal degradation of bamboo culm is summarized in table 1 .

Table 1: Effect of heating rate on thermal degradation of bamboo culm

\begin{tabular}{|c|c|c|c|c|}
\hline & Heating rate & Phase I & Phase II & \begin{tabular}{|l|} 
Phase III \\
\end{tabular} \\
\hline \multirow{3}{*}{$\begin{array}{l}10^{\circ} \mathrm{C} \\
\min ^{-1}\end{array}$} & Temperature range, ${ }^{\circ} \mathrm{C}$ & 0 to 100 & 100 to 500 & 500 to 900 \\
\hline & Weight loss, \% & 7.22 & 62.25 & 7.9 \\
\hline & $\begin{array}{l}\text { Derivative weight } \\
\text { change, } \%{ }^{\circ} \mathrm{C}^{-1}\end{array}$ & 0.62 & 3 & 0.79 \\
\hline \multirow{3}{*}{$\begin{array}{l}20^{\circ} \mathrm{C} \\
\min ^{-1}\end{array}$} & Temperature range, ${ }^{\circ} \mathrm{C}$ & 0 to 150 & 150 to 550 & 550 to 9 \\
\hline & Weig & 8.04 & 6005 & 16.78 \\
\hline & ight & 0.84 & 6. & 1.62 \\
\hline \multirow{3}{*}{$\begin{array}{l}30{ }^{\circ} \mathrm{C} \\
\min ^{-1}\end{array}$} & Temperature range, ${ }^{\circ} \mathrm{C}$ & 0 to 180 & 180 to 600 & 600 to 90 \\
\hline & Weigh & 6.63 & 69.69 & 12.69 \\
\hline & $\begin{array}{l}\text { Derivative weight } \\
\text { change, } \%^{\circ} \mathrm{C}^{-1}\end{array}$ & 0.60 & 7.00 & 1.25 \\
\hline \multirow{3}{*}{$\begin{array}{l}40^{\circ} \mathrm{C} \\
\min ^{-1}\end{array}$} & Temperature range, ${ }^{\circ} \mathrm{C}$ & 0 to 200 & 200 to 600 & 600 to 90 \\
\hline & & 8.80 & 63.48 & 3.73 \\
\hline & $\begin{array}{l}\text { Derivative weight } \\
\text { change, } \%^{\circ} \mathrm{C}^{-1}\end{array}$ & 0.83 & 6.36 & 0.37 \\
\hline
\end{tabular}

TGA plots with corresponding DTG plots at 10, 20, 30 and 40 ${ }^{\circ} \mathrm{C}$ are presented in Fig 1 to 4. DTG curve also highlighted that the thermal degradation of bamboo culm happened in three phases. Di Blasi (2008) ${ }^{[1]}$ showed that it is important to distinguish the behaviour of the three components for a better understanding of biomass thermal degradation process. The first decomposition phase occurred below $200{ }^{\circ} \mathrm{C}$ where moisture and light volatile compounds (light volatiles) were removed. This phase is considered as drying phase and 7.22, 8.04, 6.63 and $8.8 \%$ of biomass weight was lost at 10, 20, 30 and $40{ }^{\circ} \mathrm{C}$ min $^{-1}$ heating rate, respectively.

A rigorous change was observed in the peak between 200 and $600{ }^{\circ} \mathrm{C}$, and specified as the second decomposition phase. Here, the bamboo culm is largely devolatilized. The slop of TGA curves represented a substantial loss of bamboo culm due to dissociation and decomposition of molecular bonds. In this phase, volatile hydrocarbons and a major part of components viz., cellulose, hemicellulose and lignin were released, and around 68.25, 69.05, 69.69 and $68.48 \%$ of weight loss occurred at $10,20,30$ and $40^{\circ} \mathrm{C} \mathrm{min}{ }^{-1}$ heating rate, respectively. This is in accordance with the fact that among cellulose, hemicellulose, and lignin contents, the loss of hemicellulose started first and it was then overlapped with the loss of cellulose, while the loss of lignin was the slowest and occurred over a wider range of temperatures. This proved the suitability of bamboo for pyrolytic conversion than combustion and gasification.

In the third phase, remaining char material was slowly degraded at or above $500{ }^{\circ} \mathrm{C}$, and 17.9, 16.78, 13.69 and $13.73 \%$ weight loss occurred at $10,20,30$ and $40{ }^{\circ} \mathrm{C} \mathrm{min}-1$ heating rate. The residual mass was due to its higher ash and fixed carbon content (Sadhukhan et al., 2008). At closer to $900{ }^{\circ} \mathrm{C}$, the decomposition rate became stable, and the remaining mass comprising of mineral constituents termed as ash content was 6.63, 6.13, 9.99 and $8.99 \%$ at 10, 20, 30 and $40{ }^{\circ} \mathrm{C} \mathrm{min}-1$ heating rate. The obtained results showed a good reproducibility of the outcome of the study conducted by Milan and Tatjana (2018).

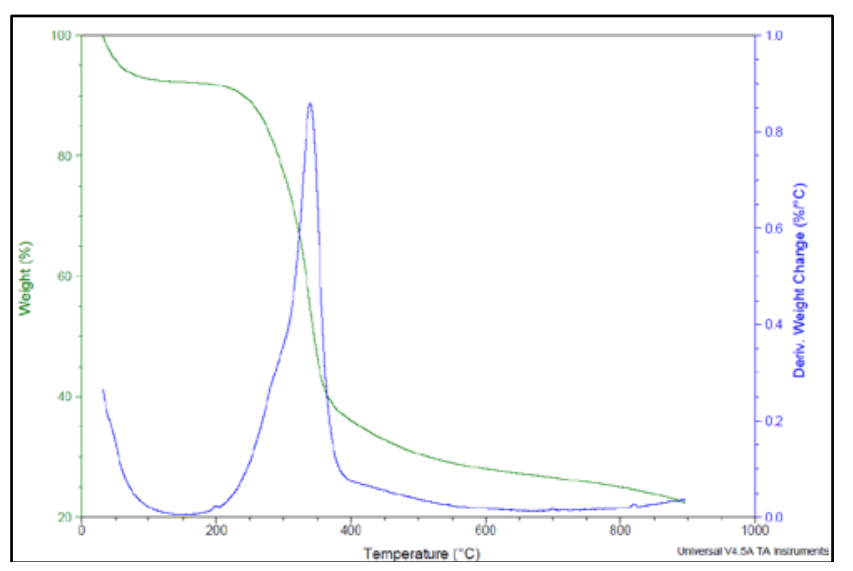

Fig 1: TGA of Bamboo culm at heating rate of $10^{\circ} \mathrm{C} \mathrm{min}-1$

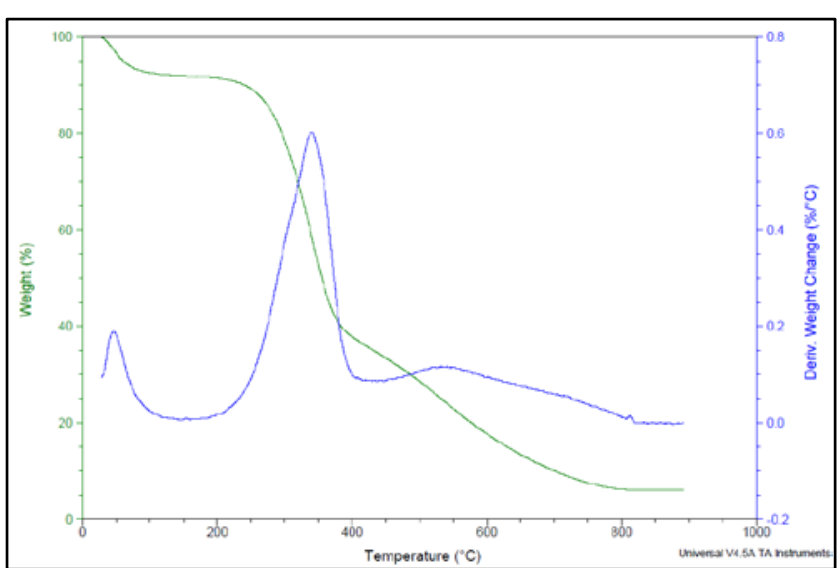

Fig 2: TGA of Bamboo culm at heating rate of $20^{\circ} \mathrm{C} \mathrm{min}{ }^{-1}$

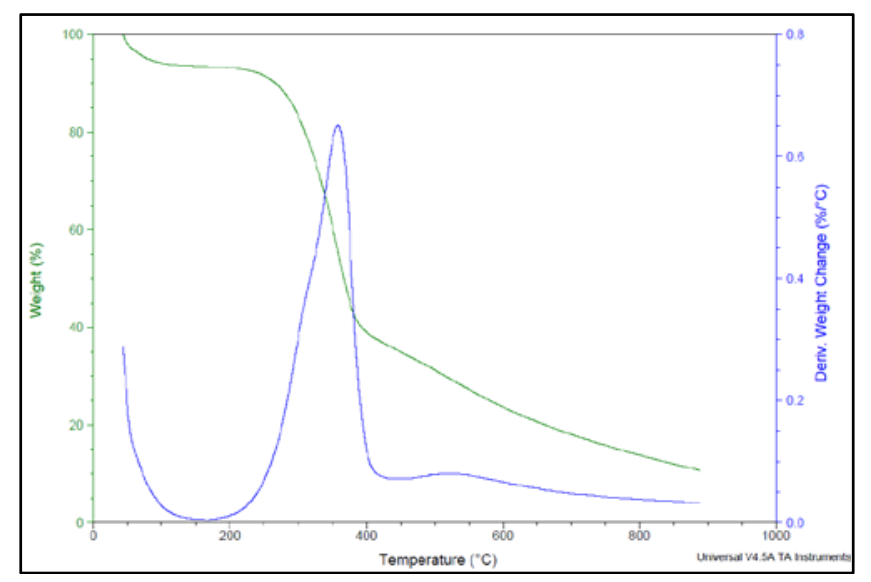

Fig 3: TGA of Bamboo culm at heating rate of $30^{\circ} \mathrm{C} \mathrm{min}-1$ 


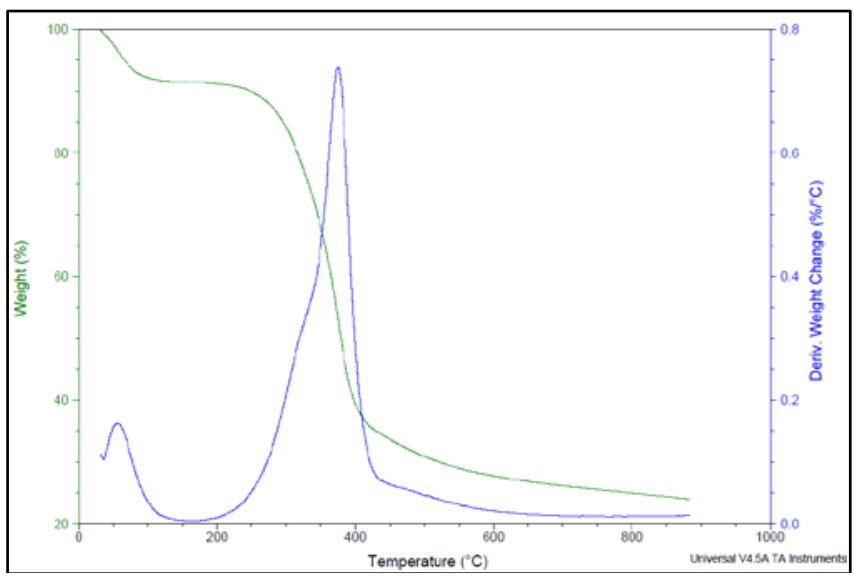

Fig 4: TGA of Bamboo culm at heating rate of $40^{\circ} \mathrm{C} \mathrm{min}-1$

The data illustrate the decomposition nature of bamboo particles such as first phase as the elimination of moisture content, second phase as the removal of major volatile matter by the degradation of hemicellulose and cellulose and third phase as the decomposition of higher volatiles and carbon (Md et al., 2020) ${ }^{[3]}$.

The weight loss was maximum in the second phase at the temperature range of 157 to $562{ }^{\circ} \mathrm{C}$ with an average weight loss percentage of 68.86. From the results it is concluded that the heating rate did not influence the thermal degradation nature of bamboo, whereas it also assessed the suitability of bamboo culm for pyrolysis process than other thermochemical conversion processes.

\section{Conclusion}

In this experimental study, thermal degradation of bamboo culm is examined through thermogravimetric analyses. TG and DTG plots were performed in an inert atmosphere at four different heating rates of $10,20,30$ and $40{ }^{\circ} \mathrm{C} \mathrm{min}{ }^{-1}$. The results indicated that the thermal degradation of bamboo culm is characterized by a three-phase reaction when subjected to increased temperature conditions. The weight loss during the first phase (water and light volatiles) was due to release of moisture from the bamboo culm. The weight loss was higher in the second phase due to degradation of volatile content and constituents of cellulose, hemicellulose and lignin. The weight loss was observed to be maximum in the second phase with an average weight loss percentage of 68.86. It is evident that the influence of heating rate on thermal degradation nature of bamboo was insignificant. The study indicates the suitability of bamboo culm for pyrolysis process

\section{Reference}

1. Di Blasi C. Modelling chemical and physical processes of wood and biomass pyrolysis. Prog Energy Combust Sci. 2008; 34:47-90.

2. Kumar A, Wang L, Dzenis YA, Jones DD, Hanna MA. Thermogravimetric characterization of corn stover as gasification and pyrolysis feedstock. Biomass and Bioenergy. 2008; 32:460-467.

3. Md Sumon Ra, Shafi NI, Shammya A, Muhammad SAB, Juntakan T, Abul KA. Data on FTIR, TGA - DTG, DSC of invasive pennisetum purpureum grass. Data in Brief. 2020; 30:105536.

4. Mlan P, Tetjana G. Thermogravimetric analysis of biomass and sub-bituminous coal. VIII International Conference Industrial Engineering and Environmental Protection; Zrenjanin, Serbia, 2018.
5. Saddawi AJ, Williams JM, Wojtowicz MA. Kinetics of the thermal decomposition of biomass. Energy Fuels 2010; 24:1274-1282.

6. Sadhukhan AK, Gupta P, Goyal T, Saha RK. Modelling of pyrolysis of coal biomass blends using thermogravimetric analysis, Bioresource Technology. 2008; 99:8022-8026. 